\title{
Quiste parauretral de Skene en niña recién nacida
}

\author{
A. Parente Hernández, J.Mํaํ Angulo Madero, A. del Cañizo López, O. Sánchez París, \\ R.Mํㅡㄹ Romero Ruiz, J. Vázquez Estévez
}

Departamento Pediatría y Cirugía Pediátrica. Servicio de Cirugía Pediátrica, Sección Urología Pediátrica. Hospital General Universitario Gregorio Marañón. Madrid.

Actas Urol Esp 2006; 30 (1): 93-94

\section{RESUMEN}

GUISTE PARAURETRAL DE SKENE EN NIÑA RECIÉN NACIDA

El quiste parauretral o quiste del conducto de Skene es una rara anomalía congénita descrita en neonatos de sexo femenino. Se trata de una formación quística que se muestra como una tumoración redonda, amarillenta o anaranjada, que se presenta adyacente al meato externo uretral. Su incidencia en la población se cifra entre 1 de cada 2.000 y 1 de cada 7.000 recién nacidos vivos femeninos. Sin embargo, sólo se recogen 47 ejemplos anteriores en la literatura en inglés. Es posible que el desconocimiento de esta patología entre la población médica y su benignidad produzcan fallos diagnósticos que infravaloren esta incidencia. Aunque existen autores que apoyan el tratamiento quirúrgico del quiste para lograr su curación, más aún a partir de los 6 meses de edad, la mayoría se ponen de acuerdo en la indicación de un tratamiento expectante dada la tendencia a la resolución espontánea. Palabras clave: Quiste parauretral. Skene. Neonato.

\section{ABSTRACT}

THE PARAURETHRAL CYST OR SKENE'S DUCT CYST IN THE FEMALE NEWBORN

The paraurethral cyst or Skene's duct cyst is a rare congenital anomaly in the female newborn. It appears like a round, yellow or orange-colored cystic mass on either side of the urethral meatus. The reported incidence is 1 in 2.000 to 7.000 female births. The low frequency of the Skene's duct cyst and the little awareness of it and its benignity may lead to wrong diagnosis that underestimates its incidence. There are authors that agree with surgical treatment of paraurethral cyst to obtain an early resolution, even though a majority agrees to manage conservatively.

Keywords: Paraurethral cyst. Skene. Newborn.

$\mathrm{E}_{\mathrm{s}}^{1}$ quiste parauretral o quiste del conducto de Skene $^{1}$ es una rara anomalía congénita descrita en neonatos de sexo femenino ${ }^{2}$. Se trata de una formación quística que se muestra como una tumoración redonda, amarillenta o anaranjada, que se presenta adyacente al meato externo uretral. Sólo se recogen 47 casos anteriores en la literatura indexada ${ }^{3-7}$, pero es posible que su incidencia sea mayor al no ser diagnosticado debido a su benignidad. Esta patologia debe incluirse en el diagnóstico diferencial de ureterocele ectópico e imperforación de himen en las recién nacidas.

\section{CASO CLÍNICO}

Recién nacida hembra, con embarazo y parto normales. En la exploración clínica se apreció una tumoración de $1 \mathrm{~cm}$ de diámetro en el introito, dura a la palpación situada ligeramente a la derecha del meato uretral, desplazando este al igual que el introito vaginal. La lesión tenía aspecto quístico de color levemente amarillento (Fig. 1). Con el diagnóstico de sospecha de Ureterocele se pidió una ecografia: no hallando ni duplicidad ni dilatación urinaria. En la ecografía perineal se confirmó la naturaleza quística de la 


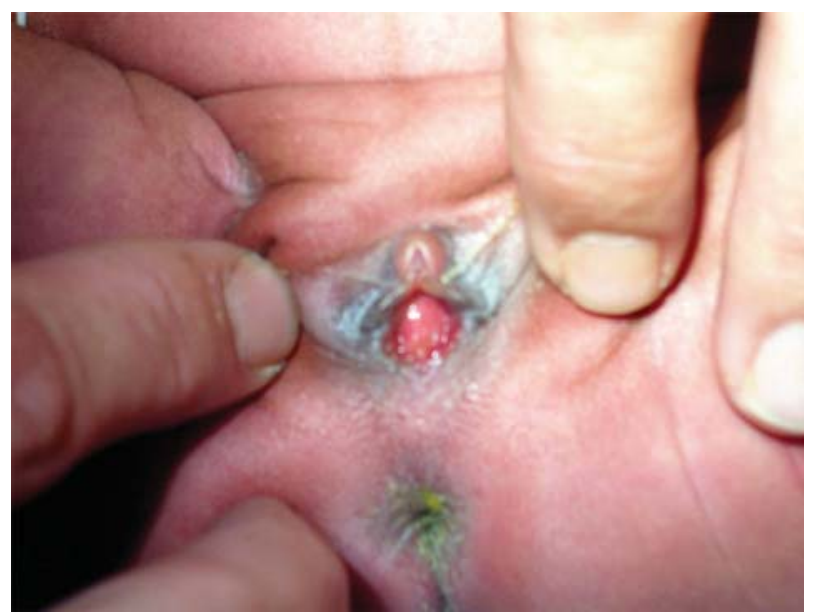

FIGURA 1.

lesión confirmándose el diagnóstico de quiste parauretral de Skene. Se decidió actitud expectante, en el seguimiento del paciente la lesión fue disminuyendo de tamaño, siendo de $5 \mathrm{~mm}$ a las 2 semanas, desapareciendo completamente la tumoración al mes de vida. No fue descrita ninguna secuela en la paciente.

\section{DISCUSIÓN}

El quiste parauretral o de Skene es una tumoración quística benigna adyacente al meato externo de la uretra. La lesión depende de las glándulas periuretrales. Estas son el equivalente femenino de la próstata masculina. En número de 6 hasta 30 , son pequeñas glándulas cuyo conducto excretor desemboca en el tercio distal de la uretra o en el introito. Existen 2 de mayor tamaño que reciben el nombre de glándulas de Skene (Fig. 2). Su función es lubricar el introito mediante su secreción mucoide durante la estimulación

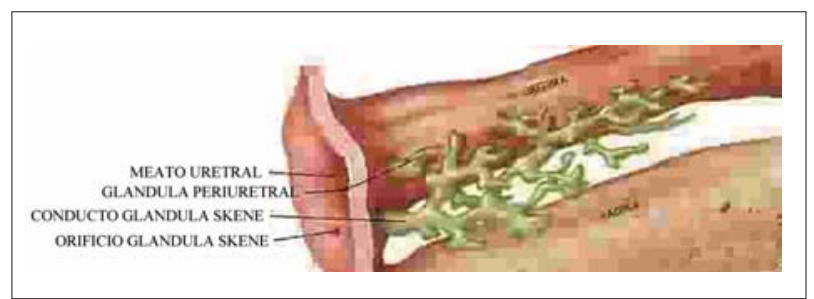

FIGURA 2 sexual. La etiopatogenia es desconocida, se piensa puede ser debido a la degeneración quística de la glándula o la obliteración de los conductos excretores.

La incidencia es desconocida, autores como Cohen $^{2}$, Lee ${ }^{3}$ y Merlob ${ }^{4}$ publican una incidencia aproximada de 1 cada 2.000-3.000 recién nacidos. Esto nos invita a pensar que la mayoría de casos pasan desapercibidos.

Todos los casos publicados son asintomáticos y habitualmente la tumoración tiende a su disolución espontánea, aunque en algunos casos como el publicado por Ceylan ${ }^{6}$ se ha observado un crecimiento en los primeros meses de vida por lo que fue necesario su tratamiento quirúrgico.

La actitud terapéutica debe ser la abstención inicialmente y si persiste la tumoración pasados 6 meses se debe realizar punción-aspiración o marsupialización de dicha tumoración, con buenos resultados en todos los casos publicados.

\section{REFERENCIAS}

1. Skene AJC. The anatomy and pathology of two important glands of the female urethra. Am J Obstet 1880;13:265266.

2. Cohen HJ, Klein MD. Cysts of the vagina in the newborn infant. Am J Dis Child 1957;94:322-324.

3. Lee NH, Kim SY. Skene's duct cysts in female newborns. J Pediatr Surg 1992;27:15-17.

4. Merlob P, Bahari C, Liban E, Reisner SH. Cysts of female external genitalia in the newborn infant. Am J Obstet Gynecol 1978; 132(6):607-610.

5. O. Herek, H. Ergin. Paraurethral cysts in nexborn: A case report and review of literature. Eur J Pediatr Surg 2000;10:65-67.

6. H. Ceylan. Paraurethral cyst: Is conservative management always appropriate? Eur J Pediatr Surg 2002;12:212-214.

7. Fathi K, Pinter A. Paraurethral cysts in female neonates. Case reports. Acta Paediatr 2003;92:758-759.

Dr. A. Parente Hernández

e-mail: parente80@hotmail.com

(Trabajo recibido el 26 de enero 2005) 